\title{
DOENÇAS DE VEICULAÇÃO HÍDRICA NO CONTEXTO ESCOLAR
}

\section{WATER-BASED DISEASES IN THE SCHOOL CONTEXT}

\section{ENFERMEDADES DE BASE DE AGUA EN EL CONTEXTO ESCOLAR}

Helder Neves de Albuquerque ${ }^{1}$

Joaci dos Santos Cerqueira ${ }^{2}$

Abraão Romão Batista ${ }^{3}$

1. Biólogo. Professor do Instituto Federal da Paraíba (IFPB) (Campus Cabedelo). Programa de Pós-Graduação Lato sensu em Desenvolvimento e Meio Ambiente - IFPB (Campus Monteiro). E-mail: helderbiologo@gmail.com

2. Universidade Federal da Paraíba (UFCG). Programa de Pós-Graduação em Engenharia e Gestão de Recursos Naturais- PPGEGRN. E-mail: cerq2006@gmail.com

3. Biólogo. Professor do Instituto Federal da Paraíba (IFPB) (Campus Monteiro). E-mail: abraao.batista@ifpb.edu.br

RESUMO: O crescimento desordenado e sem planejamento das cidades, sobretudo no semiárido brasileiro, nos alerta para questões muito preocupantes relativas ao acesso regular da população à água potável. Diante disto, objetivou-se identificar o nível conhecimento e sensibilização dos alunos do Ensino Médio em relação às doenças de veiculação hídrica e as medidas profiláticas, em duas escolas da rede Estadual de Ensino no município de Campina Grande-PB. Assim, foi realizada uma pesquisa de campo, com abordagem quali-quantitativa, através de questionários com perguntas abertas e fechados, no período de agosto a dezembro de 2019, em duas escolas de Ensino Médio da rede estadual em Campina Grande-PB. Foi possível detectar que a maioria dos alunos ainda detêm percepções fragilizadas sobre as medidas preventivas, profiláticas e de tratamentos. Desconhecem totalmente as ações do PSF junto à comunidade escolar, e a maior parte dos alunos pesquisados nunca realizaram exame parasitológico de fezes. Infelizmente, em Campina Grande-PB, as ações de educação em saúde ainda é falha junto as escolas pesquisadas e há um evidente desconhecimento sobre medidas de higiene, prevenção e tratamento das doenças de veiculação hídrica.

Palavras-chave: Programa Saúde na Escola. Comunidade Escolar. Educação em Saúde. Hábitos de Higiene.

\begin{abstract}
The disorderly and unplanned growth of cities, especially in the Brazilian semiarid region, alerts us to very worrying issues regarding the regular access of the population to drinking water. Given this, the objective was to identify the level of knowledge and awareness of high school students in relation to waterborne diseases and prophylactic measures, in two schools of the State Education network in the city of Campina Grande-PB. Thus, a field research was carried out, with a qualitative and quantitative approach, through questionnaires with open and closed questions, in the period from August to December 2019, in two high schools of the state network in Campina Grande-PB. It was possible to detect that most students still have weak perceptions about preventive, prophylactic and treatment measures. They are totally unaware of the actions of the PSF with the school community, and most of the students surveyed have never had a parasitological stool test. Unfortunately, in Campina Grande-PB, health education actions are still lacking in the schools surveyed and there is an evident lack of knowledge about hygiene measures, prevention and treatment of waterborne diseases.
\end{abstract}

Keywords: Health at School Program. School Community. Health Education. Hygiene Habits.
RESÚMEN: El crecimiento desordenado y no planificado de las ciudades, especialmente en el semiárido brasileño, nos alerta sobre temas muy preocupantes en cuanto al acceso regular de la población al agua potable. Ante esto, el objetivo fue identificar el nivel de conocimiento y conciencia de los estudiantes de secundaria en relación a las enfermedades transmitidas por el agua y las medidas profilácticas, en dos escuelas de la Red de Educación del Estado en la ciudad de Campina GrandePB. Así, se realizó una investigación de campo, con enfoque cualitativo y cuantitativo, a través de cuestionarios con preguntas abiertas y cerradas, en el período de agosto a diciembre de 2019, en dos colegios de la red estatal en Campina Grande-PB. Se pudo detectar que la mayoría de los estudiantes aún tienen percepciones débiles sobre las medidas preventivas, profilácticas y de tratamiento. Desconocen totalmente las acciones del PSF con la comunidad escolar, y la mayoría de los estudiantes encuestados nunca se han sometido a una prueba parasitológica de heces. Lamentablemente, en Campina Grande-PB, aún faltan acciones de educación en salud en las escuelas encuestadas y existe un evidente desconocimiento sobre las medidas de higiene, prevención y tratamiento de enfermedades transmitidas por el agua.

Palabras clave: Programa Salud en la Escuela. Comunidad Escolar. Educación para la Salud, Hábitos de Higiene. 


\section{Introdução}

As ações educativas são os meios para que a sociedade possa através dos atores sociais, oportunizar possibilidades de conhecimentos sistemáticos, contribuindo assim na prevenção e saúde dos envolvidos na estrutura social, e a educação é a melhor forma de introduzir novos hábitos e conceitos, contribuindo para a formação do caráter de um indivíduo. Neste sentido, o componente curricular Biologia permite que as pessoas estudem e conheçam o seu organismo, as outras comunidades bióticas, além do ecossistema, e possibilita ainda, uma maior compreensão de como os microrganismos podem ser prejudiciais ao ser humano.

Desta forma, o ambiente escolar é um espaço adequado para que se possa desenvolver ações de promoção, prevenção e educação em saúde. É justamente nesse ambiente, onde em sua plenitude permite-se alcançar a qualidade de vida e a garantia dos direitos humanos e através da apropriação dos conhecimentos, pode-se transformar as realidades e as sociedades quando se alcança e se propõe à formação de atores sociais críticos, e construtores de conhecimento transformador (PIRES et al., 2012).

Para tal efetivação foi instituído em 2007 o Programa Saúde na Escola (PSE) com a finalidade de contribuir para a formação integral dos estudantes da rede pública de educação básica por meio de ações de prevenção, promoção e atenção à saúde (BRASIL, 2011).

Observa-se assim, que algumas doenças podem ser prevenidas através de vacinas, com a imunização ativa ou mesmo através da imunização passiva quando o indivíduo adquire a doença, geralmente em doenças virais infecciosas, o que não acontece com as doenças parasitárias de veiculação hídrica (LEVINSON, 2016). Pois, a prevenção das doenças hídricas está condicionada as práticas de higiene, a infraestrutura das moradias e ao saneamento básico (BORJA, 2014).

Os desafios ao saneamento básico no Brasil relacionam-se, principalmente, com a qualificação do gasto público; com a manutenção e ampliação dos atuais recursos de investimentos; e com a melhoria da capacidade técnica, institucional e financeira dos prestadores de serviços. Dentre as ações no campo do financiamento, destaca-se, a diversificação das fontes de financiamento; a garantia da continuidade e regularidade dos investimentos; a redução do ciclo de execução dos projetos; a economia de escala para a prestação dos serviços; a recuperação de custos dos empreendimentos; e a profissionalização da gestão (SANTOS, 2011).

Portanto, a deficiência de saneamento básico e a falta de tratamento dos esgotos contaminam afluentes com microrganismos, possibilitando assim o aparecimento de doenças parasitárias tais como: amebíase, ascaridíase, cólera, enterobiose, esquistossomose, febre tifoide, giardíase, hepatite A, hepatite E, leptospirose, rotavírus e poliomielite. Neste sentido, de acordo com a Secretaria de Vigilância e Saúde, a poliomielite e a febre tifoide são doenças com tendência declinante (BRASIL, 2010).

As parasitoses apresentam alta incidência na América Latina pelas características socioeconômicas e nutricionais da população, associadas à deficiência de saneamento básico (MINÉ; ROSA, 2008). A longa persistência e as baixas dosagens medicamentosas, datam os helmintos de maior potencial de infecção que as bactérias patogênicas, seguida por protozoários, e finalmente, por vírus, considerando os de menor riscos (MOTTA; SILVA, 2002).

Os nematoides Ascaris lumbricoides, Trichuris trichiuria, Hymenolepis nana, Ancylostoma duodenale e Necator americanus, e os protozoários (Entamoeba histolytica e Giardia lamblia) são 
facilmente disseminados entre as populações com deficiências higiênicas, pela ingestão de água e alimentos contaminados (HORNINCK et al., 2013).

Retrata-se assim que em pleno ano de 2016, no Brasil, situações absurdas e precárias, pois, apenas 16\% da população (cerca de 35 milhões de pessoas), não têm acesso à água tratada; apenas $46 \%$ dos esgotos gerados no país são tratados. Dessa forma, quase metade da população brasileira ainda continua sem acesso a sistemas de esgotamento sanitário (SNIS, 2018). Portanto, estas questões vêm sendo amplamente discutidas nos diversos segmentos da sociedade, embora ações mais efetivas que conduzam à convivência harmônica do homem com a natureza, ainda sejam insuficientes. Através da Educação Ambiental nas escolas de Ensino Básico é possível atingir uma camada representativa da sociedade. Assim observa-se que muito disto não se alterou em nada, pois, somente em 2020 que foi aprovado pelo parlamento brasileiro o Marco Legal do Saneamento Básico (BRASIL, 2020).

Conforme o Programa Curricular Nacional (PCN) anos iniciais do Ensino Fundamental, o tema Meio Ambiente no projeto educativo deve ser trabalhado como uma visão ampla que envolva não só os elementos naturais do meio ambiente, mas também, os elementos construídos e todos os aspectos sociais envolvidos na questão ambiental. A escola, portanto, passa a assumir um papel de destaque devido à sua função social e por sua potencialidade para o desenvolvimento de um trabalho sistematizado e contínuo. Devendo assumir explicitamente a responsabilidade pela educação para a saúde, já que a conformação de atitudes, estará fortemente associada a valores que o professor e toda comunidade escolar transmitirão inevitavelmente aos alunos durante o convívio escolar (BRASIL, 1997).

Assim a questão ambiental deve ser considerada como um modo de ver o mundo onde se evidenciem as inter-relações e a interdependência dos diversos elementos na constituição e preservação da vida, e a faixa etária extremamente jovem apresenta um potencial ideal para a absorção de novos conceitos de ocupação do espaço geográfico e a formação de uma consciência crítica, em torno de questões e problemas ambientais. Portanto, é importante que as ações de educação ambiental e em saúde, sejam fortemente empregadas por escolas e unidades de saúde, fazendo com que a população seja responsável por suas ações, consequentemente trarão benefícios coletivos e mútuos (MARINHO et al., 2015).

Diante da realidade educacional e das questões ambientais, este trabalho objetivou identificar o nível conhecimento e sensibilização dos alunos do Ensino Médio em relação às doenças de veiculação hídrica e as medidas profiláticas, em duas escolas da rede Estadual de Ensino no município de Campina Grande-PB.

\section{Metodologia}

A pesquisa ocorreu no período de agosto a dezembro de 2019, em duas Escolas Estaduais da cidade de Campina Grande-PB, que se localiza no agreste da Borborema, a $120 \mathrm{Km}$ da capital paraibana, João Pessoa. O município possui uma população estimada de 411 mil habitantes; quanto a taxa de escolarização em crianças dos 6 a 14 anos de idade, em 2010 foi de 97,6\%; já as matrículas no Ensino Médio em 2018 foram 15.152 alunos matriculados. Na saúde, a mortalidade infantil em 2017 atingiu 13,55 de óbitos por mil nascidos vivos, e as internações por diarreia em 2016 foram de 1,7 internações por mil habitantes (IBGE, 2020). 
O estudo deu-se através da pesquisa de campo, sendo realizada em turmas do Ensino Médio do turno noturno, onde foram aplicados questionários individuais aos pesquisados, contendo 10 questões abertas e fechadas. Aplicou-se em 90 alunos(as) nas respectivas salas de aula, após uma breve explanação sobre o intuito da pesquisa e os conceitos e significação do tema "doenças de veiculação hídrica", deixou-se desta maneira os pesquisados livres para expor e responder as questões sobre a temática, de acordo com o grau de conhecimento que eles possuíam.

Assim Marconi e Lakatos (1999) enfatiza que o questionário é um instrumento desenvolvido cientificamente, composto de um conjunto de perguntas ordenadas conforme um critério predeterminado que deve ser respondido sem interferência do pesquisador.

Em relação à pesquisa de campo, Gil (2008) destaca que ela procura o aprofundamento de uma realidade específica, sendo realizada por meio da observação direta das atividades do grupo estudado e através de entrevistas ou questionários, permite-se obter explicações e interpretações do ocorrem naquela realidade.

O estudo caracterizou-se como uma investigação quali-quatitativa no qual o método de pesquisa utilizado foi o estudo de caso, por conduzir a uma análise compreensiva de uma unidade social significativa. Desta forma, o estudo atendeu os requisitos previstos na Resolução n 466/2012, que aprovou as diretrizes e normas regulamentadoras de pesquisas envolvendo seres humanos, e incorporou sob a ótica do indivíduo e das coletividades, as referências básicas da Bioética: autonomia, não maleficência, beneficência, justiça e equidade, dentre outros, visando assegurar os direitos e deveres que dizem respeito à comunidade científica, aos participantes da pesquisa e ao Estado (BRASIL, 2012).

Sendo assim, e obedecendo à resolução acima especificada, os participantes da pesquisa foram contactados com antecedência e expeliram concordância de autorização através de documentos. Ao término da investigação, os resultados foram comunicados aos estabelecimentos envolvidos, bem como, foi preservada a identidade dos participantes e dos locais da pesquisa.

\section{Resultados e Discussão}

Dos 90 questionários aplicados nas duas escolas da rede estadual pesquisadas (A e B) apenas 77 foram devolvidos, sendo, 37 que foram da escola A e 40 da escola B. Um fator social interessante a ressaltar, é o fato do gênero feminino prevalecer sobre o masculino, com predominância de $54,6 \%$.

Tabela 1. Percentual do gênero dos pesquisados por escola. 2019

\begin{tabular}{ccccccc}
\hline Sexo & Escola A & \% & Escola B & \% & Total & \% \\
\hline Masculino & 17 & 22 & 18 & 23,4 & 35 & $\mathbf{4 5 , 4}$ \\
Feminino & 20 & 26 & 22 & 28,6 & 42 & $\mathbf{5 4 , 6}$ \\
\hline Total & $\mathbf{3 7}$ & $\mathbf{4 8}$ & $\mathbf{4 0}$ & $\mathbf{5 2}$ & $\mathbf{7 7}$ & $\mathbf{1 0 0}$ \\
\hline
\end{tabular}

Fato este que não era muito comum até o início deste Século. Essa é uma mudança socioeducacional que deixa em alertas alguns educadores, pois à medida que nessa sociedade machista, o gênero feminino quebrou tabus e lutou por direitos iguais mais sólidos, quantitativamente, na sala de aula essa maioria vem se refletindo, sua condição de maioria, conforme o censo demográfico. Em relação ao pesquisados do gênero masculino, espreita-se que tem parado durante o 
trajeto escolar e ingressam cada vez mais cedo em atividades laborais e menos técnicas, isso pode ser reflexo das condições socioeconômicas atuais.

Segundo Soares et al. (2015, p. 767) "as pessoas que trabalham têm menos chance de estarem na escola, cerca de 44\% do risco dos que não trabalham". Os jovens do sexo masculino têm $20 \%$ menos risco de permanecer na escola do que aquele do gênero feminino". Os pesquisadores se preocupam com o fato de que os "meninos" começam a ficar para trás por volta da $5^{\text {a }}$ série e seguem em desvantagem até a pós-graduação. Se o sucesso do gênero feminino no âmbito escolar é motivo de comemoração, preocupa o fato do gênero masculino ir cada vez pior nos estudos.

Até os anos iniciais do Ensino Fundamental, meninos e meninas vão igualmente bem. Em seguida é evidente o fracasso escolar mais acentuado entre crianças negras do sexo masculino, conforme vêm indicando as estatísticas educacionais brasileiras há algumas décadas (NOGAREDO, 2916).

De acordo com os dados observados na Figura 1, na Escola "A" a maioria dos alunos correspondia a faixa etária entre 21 a 23 anos (18,2\%), e na escola "B", a maioria dos alunos foram da faixa etária entre 18 a 20 anos (16,9\%). Contudo, observa-se que essas faixas etárias são superiores aquelas correspondentes aos alunos caracterizados como faixa etária na idade própria, conforme preconiza a LDB/1996.

Figura 1. Faixa etária dos alunos pesquisados por escola. 2019

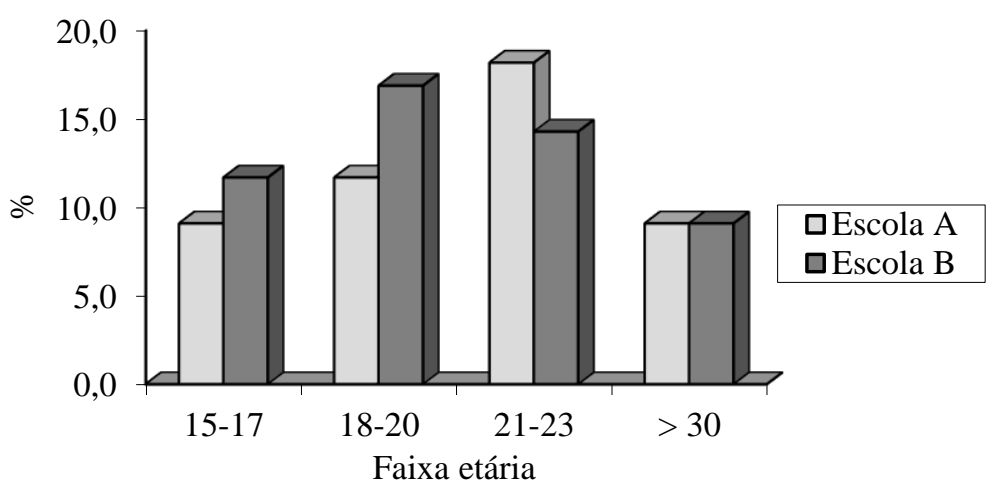

Conforme o Pesquisa Nacional por Amostra de Domicílios (PNAD) - Educação 2019 mais da metade das pessoas de 25 anos ou mais não completaram o Ensino Médio, todavia, o percentual de adultos de 25 anos ou mais que completaram o Ensino Médio cresceu, passou de 47,4\% em 2018 para 48,8\% em 2019. Sendo que 2016, esse percentual era de 45,0\% (IBGE, 2019).

No Brasil, segundo dados dos órgãos oficiais, no Ensino Médio o percentual do gênero feminino é superior ao dos homens, vários são fatores que contribuem para isso: necessidade dos meninos entrarem no mercado de trabalho mais cedo; o número de acidentes vitimando jovens do sexo masculino ser alto nessa faixa etária; a taxa de natalidade de crianças do sexo feminino ser superior; dentre outros. Assim, a inserção precoce no mercado de trabalho para jovens do sexo masculino proporciona independência financeira trazendo a oportunidade de ganho real. Embora existam fatores que atingem o sexo feminino, como o casamento e a gravidez na adolescência, o número de mulheres que cursam o Ensino Médio supera a taxa de homens (LIMA, 2014).

Em relação às séries cursadas, Figura 2, a maioria dos pesquisados cursava o $2^{\circ}$ ano do Ensino Médio (45,5\%), sendo que na Escola A 42,9\% e na Escola B 57,1\%. 
Figura 2. Distribuição dos alunos pesquisados por série que cursa e escola. 2019

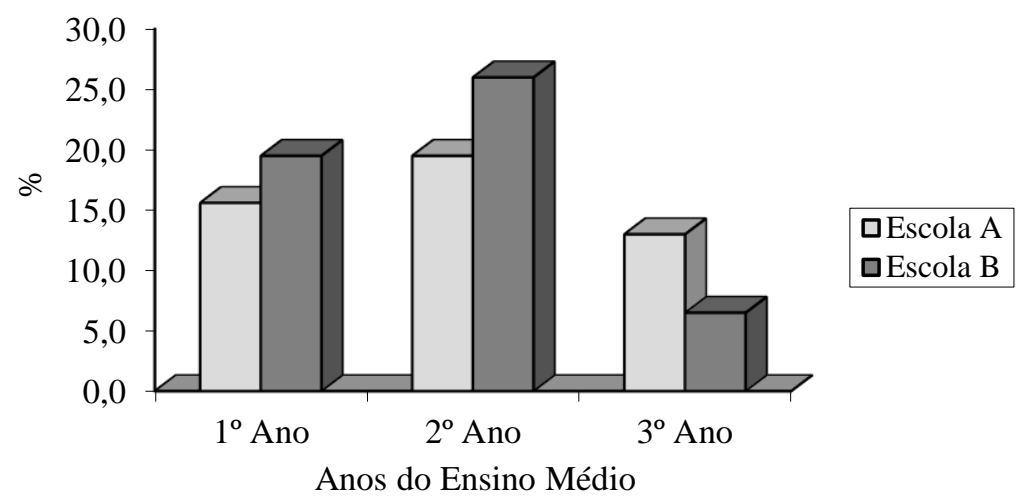

Com base nos dados do INEP (2005) foi possível afirmar que no Brasil, apenas 53,5\% dos alunos concluíam a última série do Ensino Fundamental num tempo médio de dez anos. Já no grupo etário de 15 a 17 anos, verificou-se uma desigualdade de oportunidades no acesso à escola em todos os Estados, na comparação por faixa de rendimento familiar per capita (BRASIL, 2005).

Neste sentido, muitas são as causas que levam o adolescente/jovem a evadir-se do meio escolar, dentre elas estão: as desigualdades sociais; e a distribuição de renda e deficiências no sistema educacional; o convívio familiar conflituoso, a má qualidade do ensino; outros. Salienta-se que a evasão não está relacionada apenas à escola, porém também à família, às políticas de governo e ao próprio aluno que pela situação econômica que vive não tem vontade ou não vê a necessidade da continuidade de aperfeiçoamento para futuramente ter uma profissão ou que pelo tenha concluído o ensino. Desta forma, esse contexto faz com que o estudante do Ensino Médio deixe de acreditar que a escola contribuirá para um futuro melhor, já que a educação que recebe é precária em relação ao conteúdo, à formação de valores e ao preparo para o mundo do trabalho (CABRAL, 2017).

Quanto ao conhecimento dos alunos sobre doenças de veiculação hídrica (Figura 3), a maioria $(71,4 \%)$ dos pesquisados afirmou ter conhecimento satisfatório em relação às doenças hídricas.

Figura 3. Conhecimento dos alunos sobre doenças de veiculação hídrica segundo a Escola A

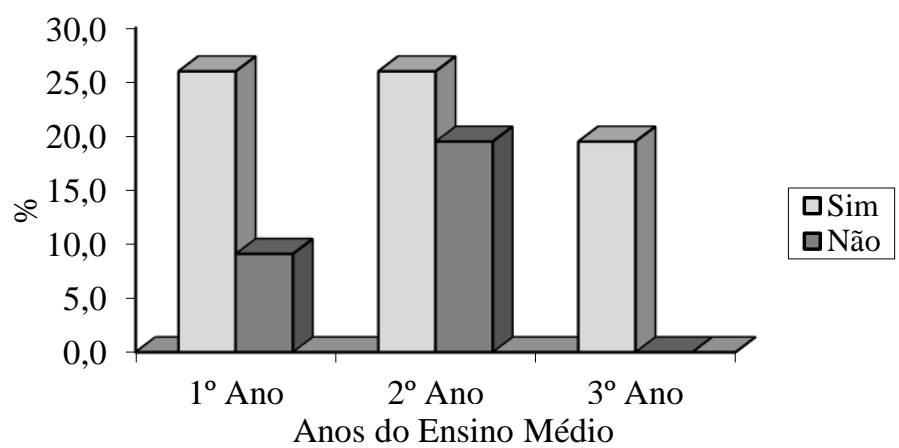

Em um estudo sobre Conhecimento da prevenção e ocorrência de parasitoses intestinais em alunos do Ensino Médio de uma escola estadual do município de Maranhãozinho-MA, Silva et al. (2020) verificaram que os alunos de Ensino Médio pesquisados possuíam pouco desconhecimento sobre as enteroparasitoses, pois, com relação ao termo "parasitoses intestinais", 52,30\% afirmaram desconhecer a definição. Assim percebeu-se nesse estudo, que o real panorama das parasitoses 
intestinais é conhecido de maneira limitada pela população avaliada, porém conseguiam assimilar com êxito algumas das principais vias de contaminação.

Conforme as respostas expressas na Figura 4, as doenças mais conhecidas identificadas pelos alunos foram respectivamente em ambas Escolas A e B: Diarreias (67,6\% e 87,5\%), Enterobioses $(59,5 \%$ e $77,5 \%)$ e amebíase $(56,8 \%$ e $70 \%)$.

Figura 4. Conhecimento dos alunos os tipos de doenças de veiculação hídrica por escola. 2019

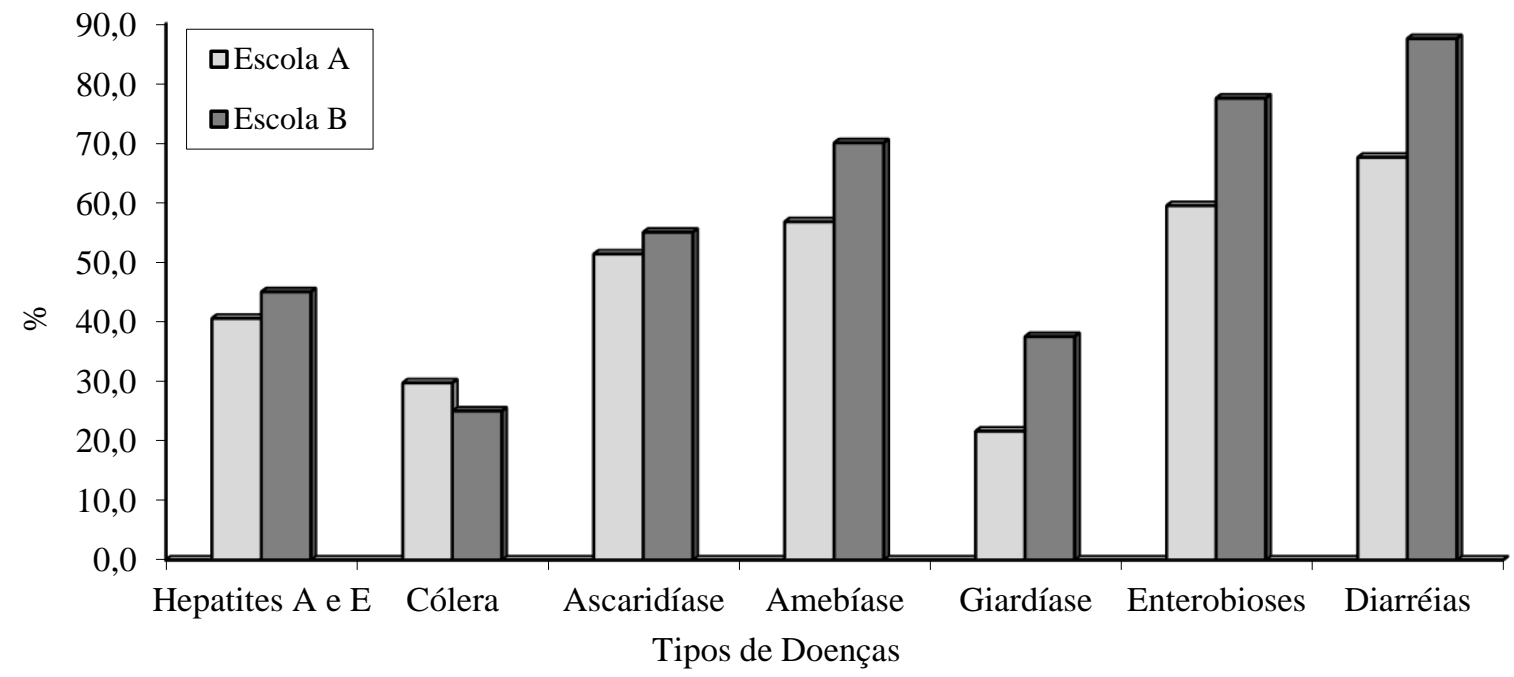

Para Currie (2017) todo cidadão deve ter consciência das relações que existem entre sua comunidade e seus membros, por um lado, e com o meio ambiente, por outro. Essas relações dependem em vários graus de variáveis sociais e culturais. Quanto mais alto for o nível de instrução, mais extensa e profunda será essa tomada de consciência. Não basta simplesmente ensinar mais a Biologia ou a Sociologia. Cada indivíduo deve conhecer o lugar que ocupa no mundo e as possibilidades de contribuir para o bem-estar dos seus concidadãos e do seu dever de evitar qualquer perturbação ao meio ambiente. Só através da educação maciça, igualitária e sem discriminação, teremos uma nação mais consciente com suas atitudes e deveres. Formando o caráter de alunos, estaremos contribuindo dentre muitas outras para educação ambiental, isso implica uma melhor utilização dos recursos hídricos, reciclagem do lixo, evitar desmatamentos e queimadas, inibindo a proliferação de microrganismos patogênicos no solo e na água.

Segundo Melo (2020), a falta de saneamento básico, além de prejudicar a saúde da população, eleva os gastos da saúde com o tratamento às vítimas de doenças causadas pela falta de abastecimento de água adequado, sistema de tratamento de esgoto e coleta dos resíduos.

A diarreia pode ter sido identificada pela maioria dos alunos por se tratar de uma situação muito comum entre as pessoas, de difícil identificação da causa, principalmente, quando não existem medidas de higiene corriqueiras. O conhecimento das enterobiose e amebíase, pode ter sido evidenciado pelas atividades trabalhadas nas aulas de biologia pelos professores nas escolas.

De acordo com a Figura 5, pode-se constatar que as medidas mais assinaladas pelos alunos para prevenção de doenças transmitidas pela água, foram: estação de tratamento de esgotos (33,8\%), seguida de Saneamento Básico $(27,3 \%)$ e das ações de tratamento da água $(18,2 \%)$. 
Figura 5. Tipos de medidas profiláticas identificadas pelos alunos por escola. 2019

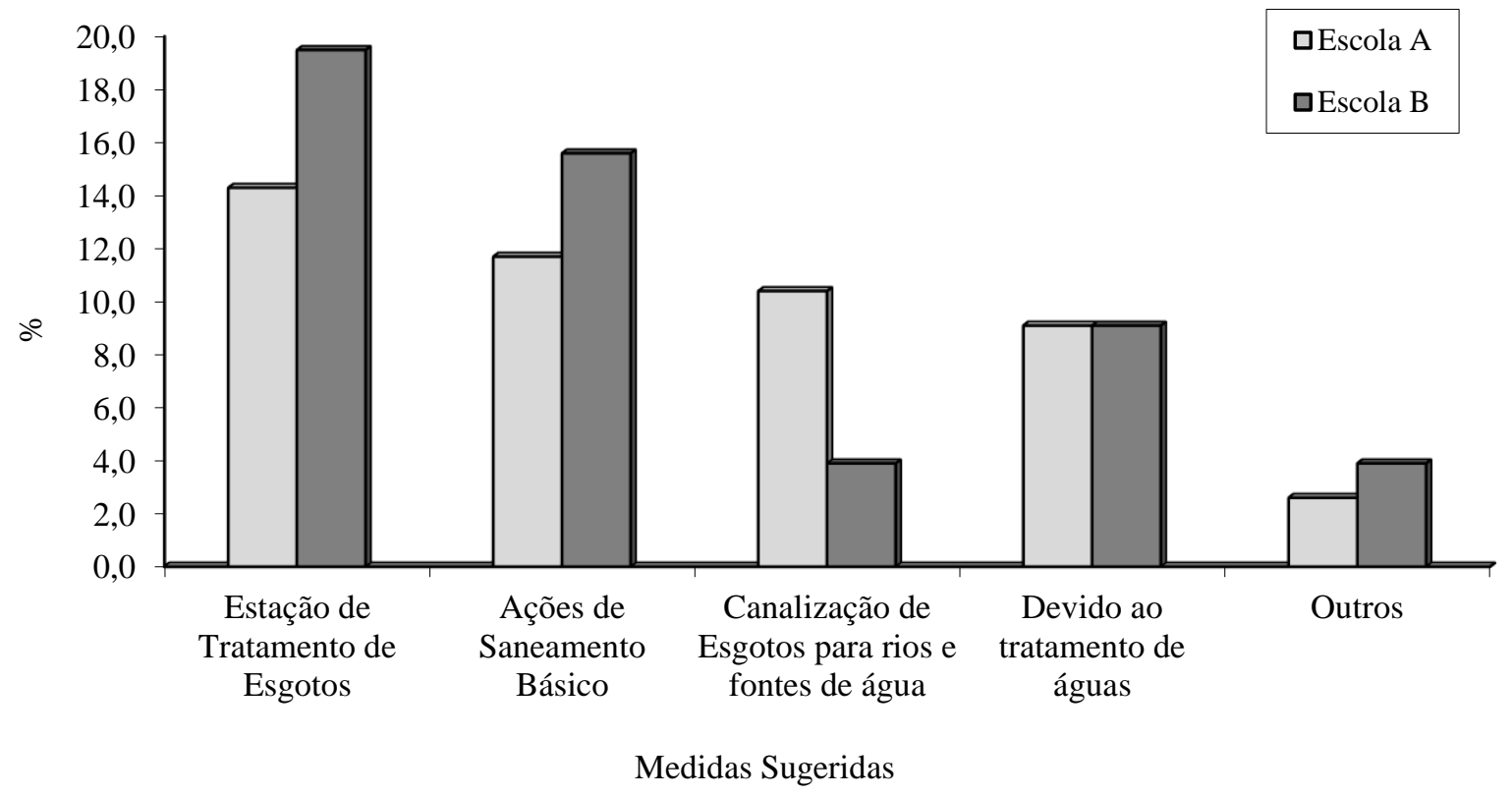

Os dados ainda evidenciam um certo desconhecimento das medidas profiláticas por parte dos alunos pesquisados, uma vez que, mesmo sendo uma medida errada, foi sugerido por eles, a canalização de esgotos para fontes de água em 14,3\% das respostas. Caso essa medida fosse empregada iria contaminar as fontes de água e solo com microrganismo.

De acordo com Nunes e Matos-Rocha (2019), em um estudo sobre fatores condicionantes para a ocorrência de parasitoses entéricas de adolescentes, com estudantes de uma escola privada do município de Maceió-AL, verificaram que os fatores associados na transmissão e a profilaxia das principais verminoses humanas estão o hábito de comer frutas e verduras e legumes crus, com $76 \%$ dos pesquisados; e quanto as medidas profiláticas, $52 \%$ deles afirmaram que não lavavam as mãos antes das refeições, ainda, todos os alunos apontaram a presença de vetores, como baratas e moscas em suas residências.

Do total de alunos pesquisados, $65 \%$ afirmaram ter sido acometidos por algum tipo de doença de veiculação hídrica, conforme Tabela 2.

Tabela 2. Frequência dos alunos que já foram acometidos por doenças de veiculação hídricas. 2019

\begin{tabular}{cccccccc}
\hline Estabelecimento de Ensino & Sim & \% & Não & \% & Total & \% \\
\hline Escola A & 30 & 39 & 7 & 9 & 37 & $\mathbf{4 8}$ \\
Escola B & 35 & 45,4 & 5 & 6,6 & 40 & $\mathbf{5 2}$ \\
\hline & Total & $\mathbf{6 5}$ & $\mathbf{8 4 , 4}$ & $\mathbf{1 2}$ & $\mathbf{1 6 , 7}$ & $\mathbf{7 7}$ & $\mathbf{1 0 0}$ \\
\hline
\end{tabular}

Os estudos de Almeida et al., (2019) corroboram com esta questão pois, verificou-se que quando se abordou sobre as doenças causadas pelo consumo de água contaminada, alguns alunos relatam já terem sido acometidos com sintomas, como dores de barriga e diarreia.

Assim, a escola tem o papel de esclarecer as dúvidas dos alunos e ao mesmo tempo conduzilos a uma amplitude de conhecimento, agindo fortemente na formação do caráter do indivíduo, 
componente de uma sociedade, se existe informação fica mais fácil conduzir a sociedade a contribuir e reivindicar medidas corretas de saneamento (SILVA et al., 2019).

Foram indagados sobre a incidência e tipos de parasitas causadores de doenças nos alunos e a maioria respondeu de forma genérica, sem identificar os parasitas como diarreias $(48,1 \%)$ e $32,5 \%$ não souberam identificar (Figura 6). Esses dados diferem de algumas literaturas que demonstram a Giardia lamblia, como parasito de maior incidência em algumas populações.

Figura 6. Incidência e tipo de parasitas causadores de doenças nos alunos por escola. 2019

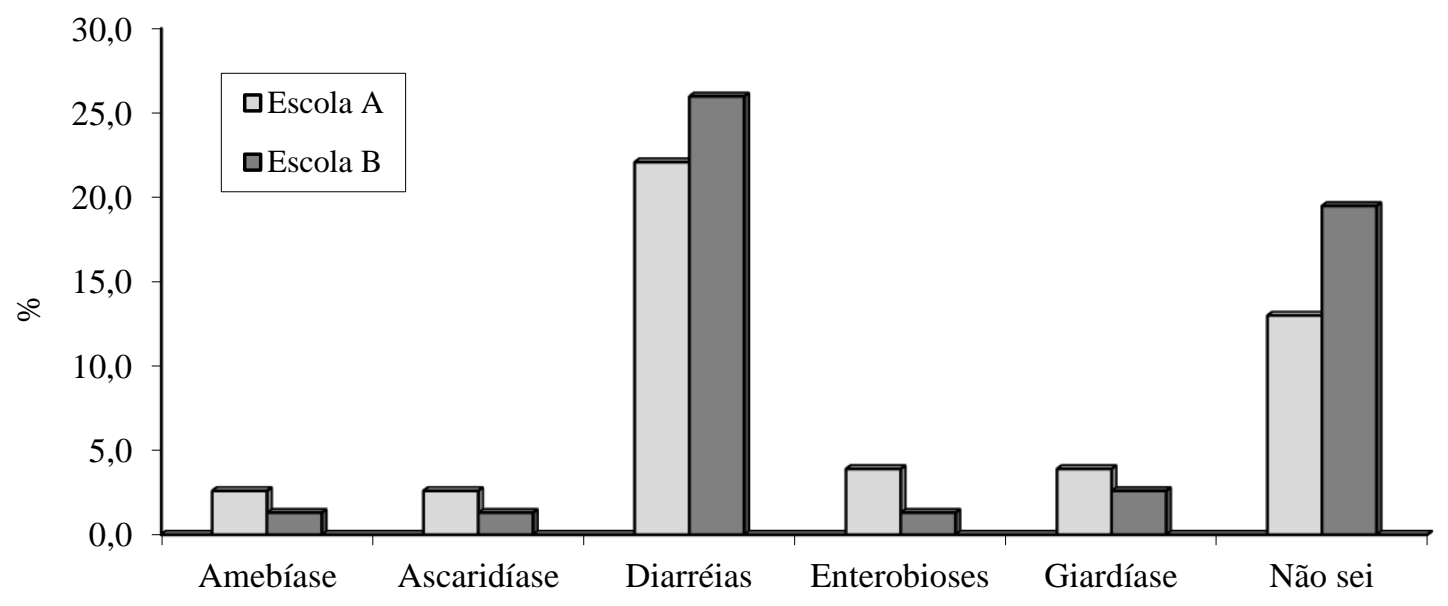

Tipos de Doenças

Segundo Sobrinho et al. (2019) as crianças em idade escolar são as mais afetadas por enteroparasitos, as quais são acometidas por deficiência nutricional, anemia, dores abdominais e até o comprometimento do rendimento escolar. Neste sentido, no estudo em uma escola municipal em Teresina-PI, sobre parasitas intestinais e o desempenho escolar de alunos, envolvendo crianças entre seis e dez anos, nos anos de 2014 e 2015, foi verificado que das 85 amostras fecais coletadas, apenas $8,23 \%$ apresentaram positividade para um ou mais parasitas intestinais. Entre os casos registrados positivos, 71,43\% foram de monoparasitismo, sendo os demais casos de triparasitismo $(28,57 \%)$ com associação aos gêneros Entamoeba histolytica/dispar, Entamoeba coli e Giardia lamblia, Enterobius vermicularis, Entamoeba coli e Giardia lamblia. Frente aos resultados apresentados, ficou evidente a relação das parasitoses à falta de saneamento básico, aos cuidados de higiene e, principalmente, pela falta de informação ou sensibilidade da população estudada quanto aos riscos e as formas de evitar as parasitoses.

Estes dados corroboram com o trabalho realizado por Costa-Lima et al. (2020) onde detectou na cidade de Campina Grande-PB uma elevada contaminação parasitária em hortaliças comercializadas (protozoários e helmintos), proporcionando uma grande problemática para a população da cidade.

De acordo com os dados coletados em relação à pergunta se eles tinham conhecimento que a escola ou a comunidade faziam algum trabalho de prevenção às doenças hídricas, 64,9\% dos alunos pesquisados afirmaram que sim (Figura 7). De acordo com as justificativas dos que afirmaram sim, disseram que apenas nas aulas dos professores em sala de aula e as demais informações foram 
adquiridas provenientes dos agentes de saúde, agentes ambientais, panfletos ou cartazes, quando estes visitam suas residências.

Figura 7. Atividades desenvolvidas pelos docentes por escola sobre prevenção de doenças de veiculação hídrica. 2019

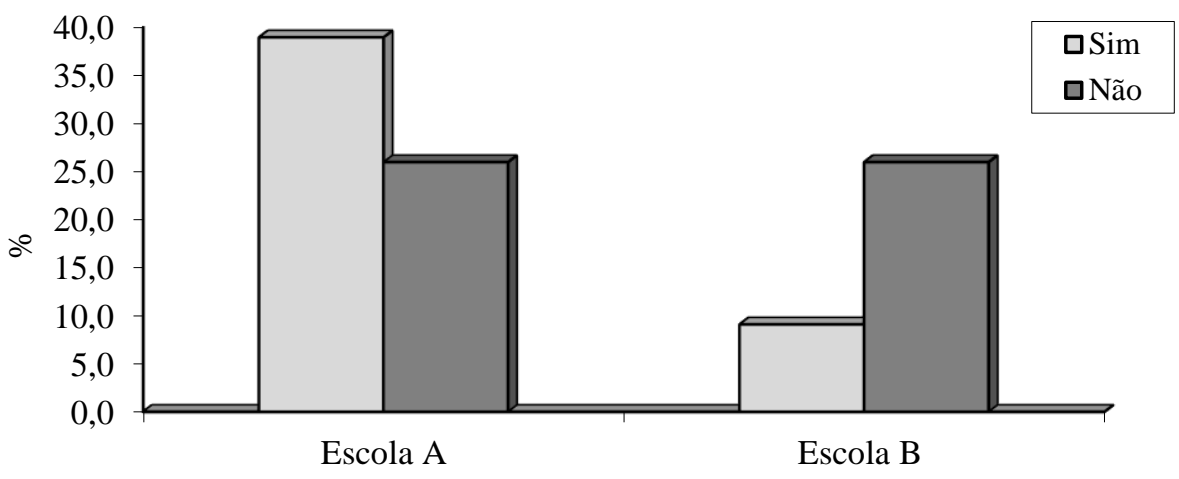

Escolas

A escola tem um papel fundamental na formação de cidadãos capazes de valorizar a saúde e participar de decisões relativas ao bem estar individual e coletivo. Desta maneira, a preocupação com a prevenção de doenças deve vir acompanhada de atitudes eficazes, construídas em conjunto, em sala de aula, e pode sim se tornar um costume, desde as fases iniciais da vida, passando a fazer parte do cotidiano. Além disso, para agirem em favor de sua saúde, as pessoas precisam se sentir capazes de atuar neste sentido, precisam se aproximar de informações seguras que direcionem suas atitudes. Portanto, um dos espaços onde podem encontrar este tipo de informações e onde crianças e adolescentes passam boa parte de seu tempo é o ambiente escolar (AMARAL et al., 2003).

Os dados obtidos nos resultados evidenciam a deficiente participação do corpo docente em temas transversos, principalmente sobre a água, que diverge das metas impostas pelos PCN`s (1997), pois, o tema meio ambiente traz a necessidade de aquisição de conhecimento e informação por parte da escola para se desenvolver um trabalho adequado junto dos alunos. Isso não implica dizer que os professores deverão "saber tudo", mas sim, dispor a aprender junto aos alunos. A educação ambiental deve ser desenvolvida a fim de ajudar os alunos a construírem uma consciência global, assumindo posições afinadas com os valores referentes à sua proteção e melhoria, estabelecendo ligações entre o aprender e o conhecer, oferecendo a compreensão de problemas que afetam sua vida, sua comunidade, a de seu país e a do planeta.

De acordo com os dados expressos na Figura 8, os alunos pesquisados das escolas A e B, respectivamente realizaram parasitológico de fezes nos últimos dois anos (13\% e 13\%), seguido dos que nunca realizaram $(13 \%$ e $11,7 \%)$ respectivamente. 
Figura 8. Frequência que os alunos, por escola, fizeram parasitológico de fezes. 2019

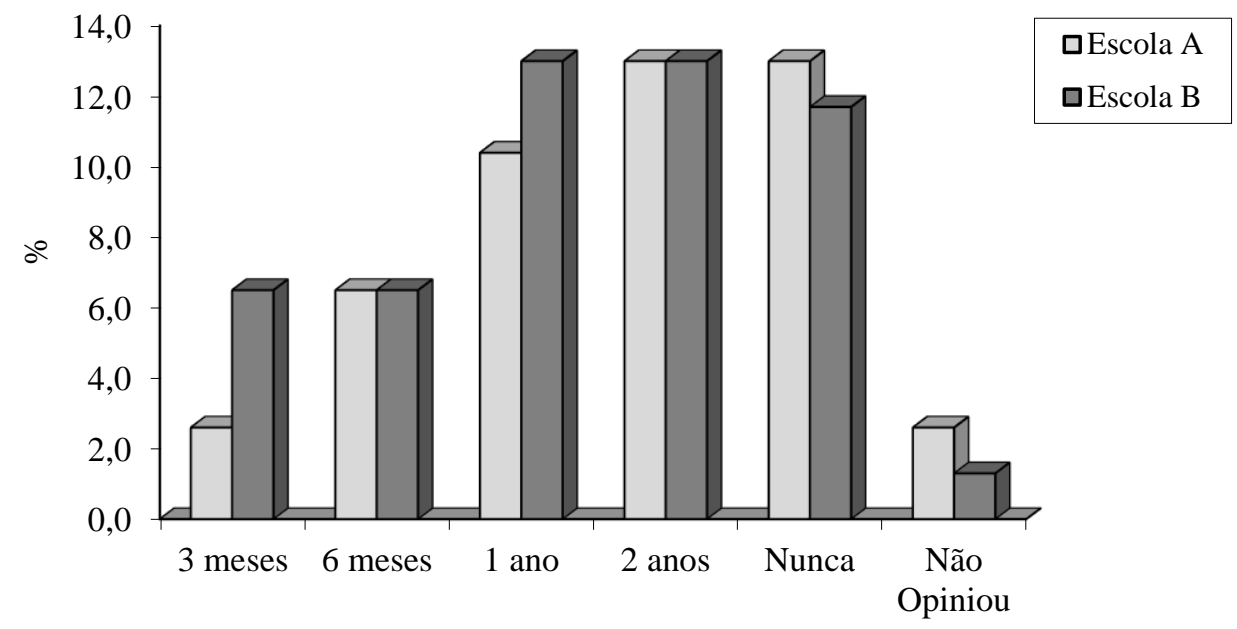

Frequência dos Exames

Conforme Rech et al. (2016), em um estudo sobre enteroparasitas e condições socioeconômicas de escolares cidade de São Marcos-RS verificou-se que 38,4\% dos pesquisados não fazem exames de fezes antes ou depois da ingestão de medicação antiparasitária, entretanto 78,9\% deles já haviam usado vermífugo, sendo $46,8 \%$ somente uma vez por ano. Também, um total de $22,1 \%$ dos responsáveis adquire a medicação para tratamento da criança quando necessário, sem prescrição médica, e a maioria dos responsáveis $(56,3 \%)$ não informou qual nome da medicação usada, e 26,3\% relataram utilizar a marca Albendazol@ para tratamento parasitário.

De acordo com os dados coletados duas escolas pesquisadas (Figura 9), a maioria dos pesquisados afirmaram ter conhecimentos/informações quanto às medidas que contribuem para evitar as doenças de veiculação hídricas $(77,9 \%)$, sendo que $3,9 \%$ não opinaram.

Figura 9. Acesso à informação sobre medidas de higiene segundo os alunos por escola. 2019

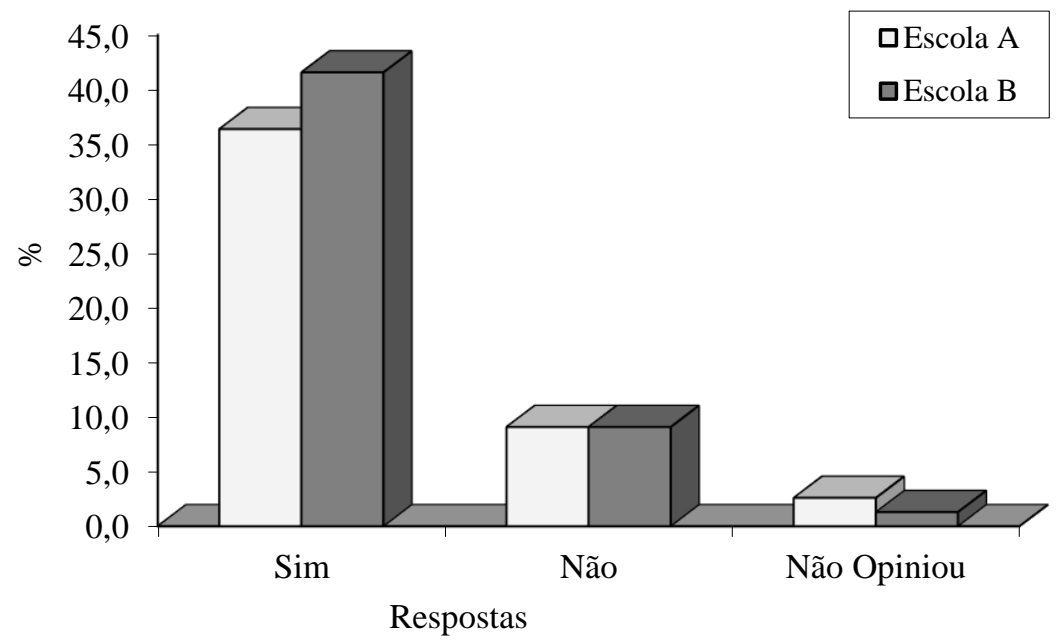

Freddo (2008) aborda que hábitos poucos saudáveis durante a fase da adolescência constituem fatores de risco para doenças e para a saúde bucal, à proporção que as medidas de higiene entrarem em conflito com o estilo de vida adotado pelos adolescentes por não quererem aceitar supervisão de 
adultos durante essa fase. Portanto, torna-se necessário que a escola entre em ação e desenvolva medidas de conscientização e sensibilização por meio de programas que sejam capazes de atender as necessidades decorrentes.

Neste sentido, Leandro e Mangiavacchi (2018) destacam que o ensino sobre parasitoses de veiculação hídrica é parte fundamental da grade curricular das escolas em diferentes anos, porém, tal ensino pode acabar gerando muitas dúvidas e poucas informações, e através dos jogos didáticos os alunos se sentem motivamos a aprender, e não apenas a memorizar temporariamente os conteúdos. Ademais, o jogo age de forma significativa mostrando a longo prazo dúvidas e dificuldades que os alunos possuem, podendo a seguir, serem sanadas por seus professores com mais clareza e eficácia.

Dos que afirmaram que a higiene contribui para a diminuição das doenças de veiculação hídrica, a maioria apontou lavar as mãos (32,9\%), consumir água tratada, filtrada ou fervida $(30,1 \%)$ e lavar os alimentos que serão consumidos $(28,8 \%)$ como as principais medidas (Tabela 3 ).

Tabela 3. Tipos de medidas de higiene descritas pelos alunos por escola pesquisada. 2019

\begin{tabular}{|c|c|c|c|c|c|c|}
\hline Medidas de Higiene & Escola A & $\%$ & Escola B & $\%$ & Total & $\%$ \\
\hline Lavar as mãos & 8 & 9,6 & 17 & 23,3 & 25 & 32,9 \\
\hline $\begin{array}{l}\text { Consumir água tratada, filtrada ou } \\
\text { fervida }\end{array}$ & 10 & 13,7 & 12 & 16,4 & 22 & 30,1 \\
\hline Andar calçados & 2 & 2,7 & 3 & 4,1 & 5 & 6,8 \\
\hline $\begin{array}{l}\text { Lavar os alimentos que serão } \\
\text { consumidos. }\end{array}$ & 2 & - & 21 & 28,8 & 23 & 28,8 \\
\hline $\begin{array}{l}\text { Evitar contato direto de esgotos com a } \\
\text { pele. }\end{array}$ & 1 & 1,4 & 1 & - & 2 & 1,4 \\
\hline $\begin{aligned} & \text { Total } \\
&\end{aligned}$ & 23 & 27,4 & 54 & 72,6 & 77 & 100 \\
\hline
\end{tabular}

De acordo com Silva e Leda (2012), em um estudo sobre a intervenção educativa relacionada a parasitoses intestinais através da utilização de um método lúdico, verificaram que percentual maior abordado pelos alunos pesquisados foi referente aos hábitos de higiene como, lavar as frutas antes de comer, beber água filtrada e sempre lavar as mãos após sair do banheiro. Desta forma, o jogo da saúde foi aceito entre os alunos pesquisados, o que permitiu aos estudantes uma participação de forma intensa, descontraída e interativa, onde facilitou o aprofundamento dos assuntos abordados durante a palestra. Para Santiago et al. (2012), um grande número de doenças pode ser evitado com o simples hábito de lavar bem as mãos após o contato com objetos possivelmente contaminados: sapatos, roupas sujas, vasos sanitários e pias sujas, solos e materiais em putrefação.

As medidas afirmadas pelos alunos são similares as propostas por Santos (2011), que descreveu sobre medidas simples que devem ser adotadas a fim de prevenir parasitoses, dentre elas: 1. Higiene corporal; 2. Lavagem adequada dos alimentos; 3. Uso de água filtrada ou fervida; 4. Andar sempre com os pés calçados; 5 . Evitar contato com solo contaminado, esgoto e fezes; 6 . Manter limpa a casa (instalações sanitárias, roupas de cama, toalhas e roupas íntimas) e o terreno ao redor; 7. Conservar as mãos sempre limpas, as unhas aparadas, evitar colocar a mão na boca; 8 . Não deixar as crianças brincarem em terrenos baldios, com lixo ou água poluída.

Quando os alunos pesquisados foram indagados se existia algum Programa desenvolvido na Escola como Saúde na Escola e se este prevenia as doenças parasitológicas, as respostas foram "Não" em 68,8\% das respostas e 10,4\% preferiram não opinar (Figura 10). 
Figura 10. Atuação do PSF na sua comunidade e na escola. 2019

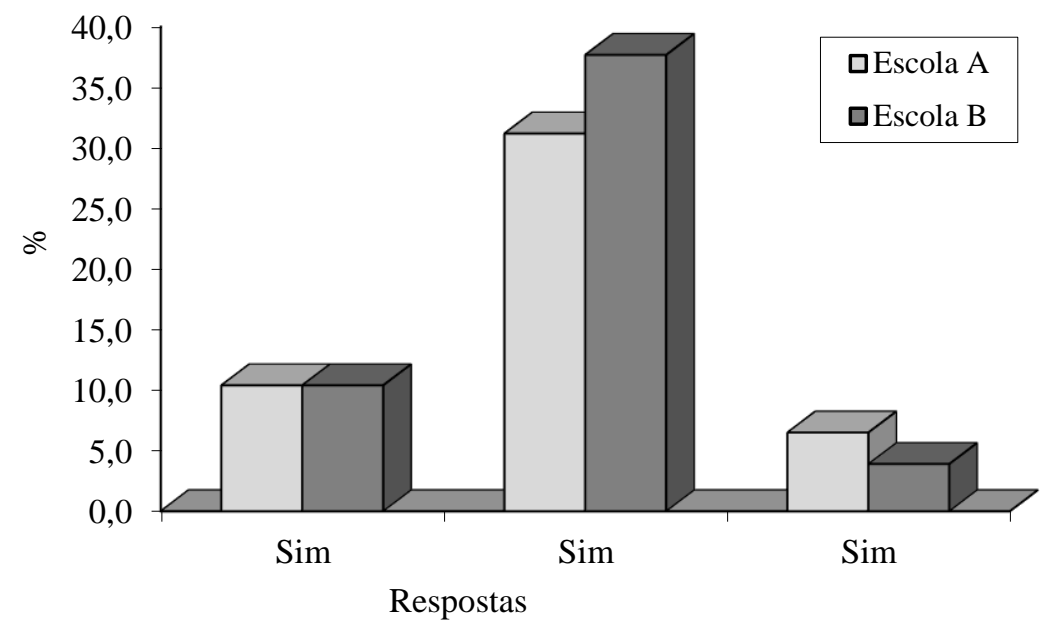

Divergindo dos resultados deste estudo Santiago et al. (2012) relatam a experiência da implantação do Programa Saúde na Escola (PSE) por uma equipe da Estratégia Saúde da Família (ESF) em uma escola pública em Fortaleza-CE. Onde as atividades desenvolvidas incluíam seminário de implantação do PSE com os docentes e integrantes da ESF, além de oficinas com os estudantes, avaliação clínica e odontológica dos adolescentes e entrega de Cadernetas de Saúde do Adolescente. Assim, a implantação do PSE permitiu aos profissionais de saúde a percepção do seu papel social de educador e possibilitou aos adolescentes maior contato com a equipe da ESF.

Também foram indagados sobre existir um PSF na localidade de suas residências e todas foram unânimes em responder que existe um PSF que atende o bairro onde residem. Com isto, perguntamos se eles conheciam se existe algum trabalho/ação/Programa de prevenção que esse PSF desenvolve nas residências e/ou Escola do bairro onde está situado o PSF e maioria respondeu que "Não" (61\%) E 18,2\% preferiram não opinar (Figura 11).

Figura 11. Prevenção desenvolvidas pelos PSF’s, nos bairros próximos às escolas pesquisadas. 2019

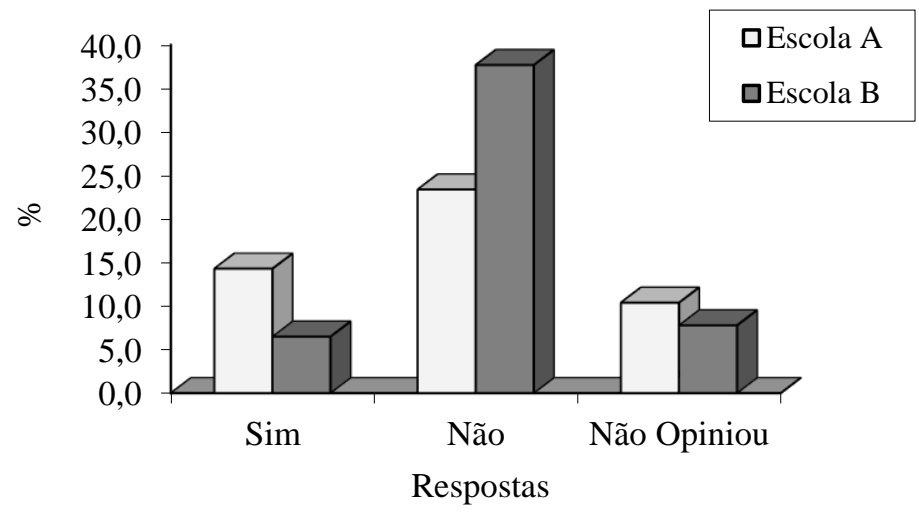

Esses resultados divergem das metas impostas pelo Caderno de Atenção Básica, produzido pelo Ministério da Saúde. Segundo o Ministério da Saúde a USF (Unidade Básica da Família), deve se constituir no primeiro contato do usuário com sistemas de saúde, isto é, a "porta de entrada" do sistema. Mas essa imagem de "porta de entrada" é apenas parcial e da margem e alguns equívocos. 
Ludwing et al. (1999), admitem que o saneamento ambiental é deficiente e está diretamente relacionado com os altos índices de parasitoses intestinais. Contudo, Ferreira e Monteiro (2000) enfatizam que os estudos sobre prevalência de enteroparasitoses no Brasil ainda são carentes e dispersos, sendo a maioria realizada em amostras de bases populacionais mal definidas como usuários de serviços de saúde, alunos de escolas públicas e comunidades urbanas carentes.

Segundo Faria (2015), no Brasil, para reduzir a prevalência das parasitoses intestinais exigese uma associação de medidas que envolvam o saneamento ambiental, a educação sanitária e o tratamento eficaz dos indivíduos infectados. Para Vasconcelos (1999) o que ainda se observa nos PSF's é uma prática tradicional, centrada no indivíduo em detrimento da família. O eixo de atuação da Estratégia tem sido os programas de assistência à saúde preconizados pelo Ministério da Saúde, a saber, materno-infantil, controle da tuberculose, da hanseníase, hipertensão arterial, imunização, e os demais. O que, se por um lado, contribui para expandir o PSF, por outro, o reduz ao desconsiderar a complexidade do que ocorre em nível local.

Uma USF não pode ser apenas um local de triagem e encaminhamento, onde maior parte dos casos são encaminhados para os serviços especializados, ela tem que ser resolutiva, com profissionais capazes de assistir aos problemas de saúde mais comuns e de manejar novos saberes que, por meio de processos educativos, promovam a saúde e previnam doenças em geral.

É necessário promover a mudança de hábitos e costumes alimentares, promover a atividade física e promover a higiene pessoal, do domicilio e do ambiente em geral. É preciso garantir água potável, vacinar animais, cuidar do destino do lixo e do esgotamento sanitário. Enfim há uma série de atividades individuais e coletivas que precisam ser promovidas e fomentadas pelas USF em conjunto com a comunidade.

Os PSF`s além de trabalhar com a saúde curativa, a principal prioridade é a prevenção, na qual estão inseridas: saúde da mulher, da criança, grupos de hiperdia, saúde mental, planejamento familiar entre outras atribuições. A escola como formadora de opiniões deve despertar em seus alunos o interesse de desenvolver trabalhos junto aos PSF's, através de um convite formulado a uma equipe de PSF, os benefícios serão mútuos, pois os alunos agirão como multiplicadores de informação junto à comunidade em que residem.

Perguntamos aos alunos se eles faziam ou fizeram uso de automedicação contra parasitos humanos e a maioria afirmou que não $(63,6 \%)$. Porém, os 26\% que afirmaram "Sim", descreveram que os principais medicamentos usados são Mebendazol; Albendazol; Ascaridil e Secnidazol ou produtos naturais a base de alho; outros afirmaram fazer uso de medicação indicadas na farmácia e não lembra o nome. 
Figura 12. Automedicação usadas pelos alunos por escola. 2019

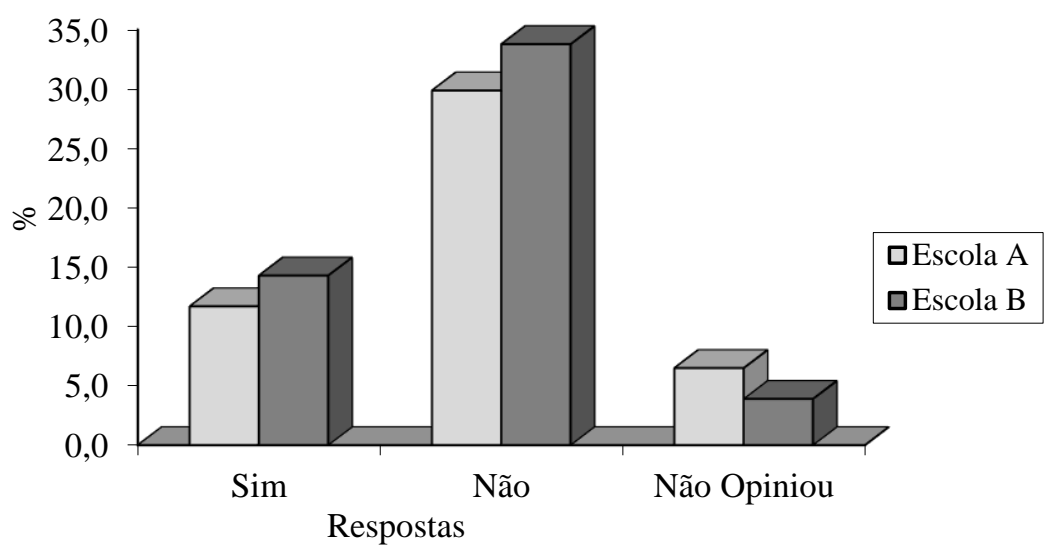

Silva et al. (2011) pesquisando sobre automedicação na adolescência em dez escolas do município de Fortaleza-CE verificaram que dentre as classes de medicamentos mais citadas, estavam os analgésicos, com $340(65,4 \%)$ relatos, os antigripais, com 64 (12,3\%), os antitérmicos, com 61 $(11,7 \%)$, e os antimicrobianos, com 51 (9,8\%). Acrescenta-se ainda que os alunos referiram o uso de uma variedade de outros medicamentos com diversas indicações terapêuticas. Assim, observou-se ainda que dos 192 alunos da Escola Pública 9 (3\%) pesquisados afirmaram realizar a automedicação através do uso de vermífugos, e dos pesquisados que fizeram uso de medicamentos, 266 (51,2\%) tiveram indicações por parte de familiares, $172(33,1 \%)$ através de médicos e $108(20,8 \%)$ foram por conta própria. Desta maneira, a indicação por médicos $(38,9 \%)$ e a automedicação $(28,1 \%)$ foram maiores para alunos das escolas privadas.

O Mebendazol, Albendazol e Ascaridil são medicações que atuam como anti-helmíntico e vão reagir contra a Ascaris lumbricoides, Enterobius vermiculares e Giardia duodenalis; já o Secnidazol, tem ação contra a Amebíase intestinal, Amebíase hepática e Tricomoníase.

\section{Conclusões}

O aumento de casos das Doenças Infecciosas e Parasitárias são considerados um problema de saúde pública, principalmente as transmitidas pela água, devido aos maus hábitos de higiene e a precária infraestrutura de saneamento básico, que tem como consequência o aumento das parasitoses nos humanos.

Assim, conclui-se que o nível de conhecimento dos alunos pesquisados nas duas escolas é precário, principalmente, no ensino de biologia e além dos programas de saúde, que precisam de uma melhor exposição dos seus conteúdos, sendo, portanto, os temas transversais, a melhor maneira de levar informações atuais para o cotidiano dos alunos. Constatou-se que os alunos já conheciam o termo D. V. H, porém em ambas as escolas, há um desconhecimento ou falta de sensibilização sobre prevenção, tratamento e medidas de higiene dessas doenças.

Atinente à identificação das principais D. V. H, apresentadas no questionário, o maior conhecimento apresentado, se deu em relação as ascaridíase e amebíases. 
Os pesquisados relataram também que possuem dificuldades quanto ao tema abordado e gostariam de obter mais informações quanto à taxonomia dos parasitos, formas de contágio, habitats naturais e medidas de prevenção e tratamento, o que evidencia que não existem atividades nas escolas ou em campo para superar estas dificuldades. Diante desta lacuna escolar, os alunos mostraram dificuldades em identificar a hepatite A e E, além das giardíases como D.V.H.

Quanto as ações preventivas e profiláticas dos PSF's, nos bairros em que residem e que as escolas estão inseridas, as ações são deficientes e não conseguiram identificar nenhuma atividade desenvolvida nesse sentido, junto à comunidade. Finalmente, constatou-se que o acesso às Unidades de Saúde da Família é difícil, por isso não costumam frequentar, o que implica na grande quantidade de alunos que nunca realizaram parasitológico de fezes, desconhecendo se tem algum tipo parasito intestinal.

\section{Referências}

ALMEIDA, A. M. M. et al. Condições socioambientais e sua relação com enteroparasitoses em escolares do ensino fundamental I. 2020.

AMARAL, L. A.; NADER FILHO, A.; ROSSI JUNIOR, O. D.; FERREIRA, F. L. A. BARROS, L. S. S. Água de consumo humano como fatos de risco à saúde em propriedades rurais. Revista Saúde Pública, São Paulo, v. 37, n. 4, p. 510-514, 2003.

BORJA, P. C. Política pública de saneamento básico: uma análise da recente experiência brasileira. Saúde e Sociedade, v. 23, p. 432-447, 2014.

BRASIL. Conselho Nacional de Saúde. Resolução n ${ }^{\circ}$ 466, de 12 de dezembro de 2012a. Aprova normas regulamentadoras de pesquisas envolvendo seres humanos. Brasília: Diário Oficial da União, 2012.

BRASIL. Lei Federal n ${ }^{\circ}$ 9.394, de 23 de dezembro de 1996. Lei de Diretrizes e Bases da Educação. 1996.

BRASIL. Lei no 14.026, de 15 de julho de 2020. Atualiza o marco legal do saneamento básico. Diário Oficial da União: seção 1, Brasília, DF, ano 158, n. 135, p. 1-26, 16 jul. 2020.

BRASIL. Ministério da Saúde. Secretaria de Atenção à Saúde. Departamento de Atenção Básica. Ministério da Educação. Passo a Passo PSE. Programa Saúde na Escola: tecendo caminhos da intersetorialidade, 2011.

BRASIL. Ministério da Saúde. Secretaria de Vigilância em Saúde. Departamento de Vigilância Epidemiológica. Doenças infecciosas e parasitárias: guia de bolso. 8. ed. rev. Série B. Textos Básicos de Saúde. Brasília: Ministério da Saúde, 2010. 444 p.

BRASIL. Ministério de Educação e Cultura. Instituto Nacional de Estudos e Pesquisas Educacionais Anísio Teixeira (Inep). 2005. Disponível em: http://inep.gov.br/artigo//asset_publisher/B4AQV9zFY7Bv/content/cresce-presenca-das-mulheres-em-todos-os-niveis-deensino/21206. Acesso em: 18 nov. 2020. 
CABRAL, C. G. L. Evasão Escolar: O que a escola tem a ver com isso? Trabalho de Conclusão de Curso (Educação e Direitos Humanos) - Universidade do Sul de Santa Catarina, 2017.

COSTA LIMA, J. L.; NASCIMENTO SILVA, A. R.; MACIEL, M. A. V. Contaminação parasitológica em alfaces (Lactuca sativa) comercializadas em Campina Grande-PB. Psicologia e Saúde em debate, v. 6, n. 1, p. 60-69, 2020.

CURRIE, K. L. Meio ambiente: interdisciplinaridade na prática. Papirus Editora, 2017.

FARIA. C. R. Educação em saúde: uma ferramenta para a prevenção e controle de parasitoses intestinais na estratégia saúde da família. Trabalho de Conclusão de Curso (Estratégia Saúde da Família) - Universidade Federal do Triângulo Mineiro, Uberaba, 2015.

FERREIRA, C. S; MONTEIRO, C. A. Tendência secular das parasitoses intestinais na infância na cidade de São Paulo (1984-1996). Revista de Saúde Pública, v. 34, n. 6, p. 73- 82, 2000. In: Plano Nacional de Controle e Vigilância das Enteroparasitoses, p. 10. Secretaria de Vigilância em Saúde do Ministério da Saúde, Brasília-DF, 2000.

FREDDO, S. L. Hábitos de higiene bucal e utilização de serviços odontológicos em escolares de uma cidade da região sul do Brasil. Caderno de Saúde Pública, Rio Janeiro, v. 24, n. 9, set., 2008.

GIL, A. C. Como elaborar projetos de pesquisa. 4. ed. São Paulo: Atlas, 2008.

HORNINK, G. G. et al. Principais parasitos humanos de transmissão hídrica ou por alimentos. Unifam-MG, 2013.

INSTITUTO BRASILEIRO DE GEOGRAFIA E ESTATISTICA (IBGE). Agência de notícias. 2019. Disponível em: https://agenciadenoticias.ibge.gov.br/agencia-sala-de-imprensa/2013-agenciade-noticias/releases/28285-pnad-educacao-2019-mais-da-metade-das-pessoas-de-25-anos-ou-maisnao-completaram-o-ensinomedio\#: :text=No\%20Brasil\%2C\%20a\%20propor\%C3\%A7\%C3\%A3o\%20de,era\%20de\%2045\% 2C0\%25. Acesso em: 18 dez. 2020.

INSTITUTO BRASILEIRO DE GEOGRAFIA E ESTATISTICA (IBGE). Panorama das cidades. 2020. Disponível em: https://cidades.ibge.gov.br/brasil/pb/campina-grande/panorama. Acesso em: 18 jan. 2021.

LEANDRO, G. O.; MANGIAVACCHI, B. M. Jogo de cartas sobre parasitoses de veiculação hídrica: uma proposta pedagógica para o ensino de biologia para alunos do ensino médio. Multiplos@cessos, v. 3, n. 2, jun.dez., 2018.

\section{LEVINSON, W. Microbiologia Médica e Imunologia. Porto Alegre: AMGH, 2016.}

LIMA, L. N. As causas do abandono escolar no primeiro ano na escola de Ensino Médio:

Fatores contribuintes para a evasão no primeiro ano do ensino médio baseado nos dados da escola maria marina soares em Guaraciaba do Norte - CE. 2014. Disponível em:

https://meuartigo.brasilescola.uol.com.br/educacao/as-causas-abandono-escolar-no-primeiro-anona-escola-ensino-medio-maria-marina-soares.htm. Acesso em: 5 dez. 2020. 
LUDWIG, M. K. et al. Correlação entre condições de saneamento básico e parasitoses na população de Assis, estado de São Paulo. Revista da Sociedade Brasileira de Medicina Tropical, Uberaba MG. v. 32, p. 55-547, 1999.

MARCONI. M. A.; LAKATOS, E. M. Técnicas de pesquisa. São Paulo: Atlas, 1999.

MARINHO, J. C. B.; SILVA, J. A.; FERREIRA, M. A educação em saúde como proposta transversal: analisando os Parâmetros Curriculares Nacionais e algumas concepções docentes. História, Ciências, Saúde-Manguinhos, v. 22, n. 2, p. 429-444, 2015.

MELO, J. E. P. Levantamento dos impactos inerentes à inadequação do saneamento básico. 2020.

MINÉ, J. C.; ROSA, J. A. Frequency of Blastocystis hominis and other intestinal parasites in stool samples examined at the Parasitology Laboratory of the Scholl of Pharmaceutical Sciences at the São Paulo State University, Araraquara. Rev. Soc. Bras. Med. Trop., v. 41, n. 6, p. 565-69, 2008.

MOTTA, M. E. F. A.; SILVA, G. A. P. Diarréia por parasitas. Rev. Bras. Saúde Mater. Infant., Recife, v. 2, n. 2, p. 117-127, Aug. 2002. Disponível em.

http://www.scielo.br/scielo.php?script=sci_arttext\&pid=S1519-

$38292002000200004 \& \operatorname{lng}=e n \& n r m=$ iso. Acesso em: 25 dez. 2020.

NOGAREDO, A. A. S. Aspectos sociais, culturais e escolares das crianças que reprovam no $3^{\circ}$ ano do ensino fundamental, no estado de Santa Catarina. 2016.

NUNES, M. O.; MATOS-ROCHA, T. J. Fatores condicionantes para a ocorrência de parasitoses entéricas de adolescentes. J. Health Biol Sci. v. 7, n. 3, p. 265-270, 2019.

PIRES, L. M.; QUEIRÓS, P. S.; MUNARI, D. B.; MELO, C. F.; SOUZA, M. M. S. A Enfermagem no Contexto da Saúde do Escolar: Revisão Integrativa da Literatura. Rev. Enferm. UERJ, Rio de Janeiro, v.20, n5, p.668-675 dez. 2012.

RECH, S. C.; CAVAGNOLLI, N. I.; SPADA, P. K. W. D. S.; RODRIGUES, A. D. Frequência de enteroparasitas e condições socioeconômicas de escolares da cidade de São Marcos-RS. Semina: Ciências Biológicas e da Saúde, Londrina, v. 37, n. 1, p. 25-32, jan./jun. 2016.

SANTIAGO, L. M.; RODRIGUES, M. T. P.; OLIVEIRA JUNIOR, A. D.; MOREIRA, T. M. M. Implantação do Programa Saúde na Escola em Fortaleza-CE: atuação de equipe da Estratégia Saúde da Família. Rev Bras Enferm, Brasília, v. 65, n. 6, p. 1026-9, nov-dez., 2012.

SANTOS, J. F. Investimentos em saneamento básico nos últimos 10 anos e a projeção de investimentos do PLANSAB. Brasília: Ministério das Cidades, 2011.

SILVA, A. B. C.; VIEIRA, I. R. S.; FIRMO, W. C. A.; ALIANÇA, A. S. S. Conhecimento acerca da prevenção e ocorrência de parasitoses intestinais em alunos do Ensino Médio de uma escola estadual do município de Maranhãozinho-MA. Research, Society and Development, v. 9, n. 7, 2020. 
SILVA, E. M. M. et al. O estudo das enteroparasitoses como subsídio para melhoria do ensino de Biologia e promoção da saúde. 2019.

SILVA, I. M.; CATRIB, A. M. F.; MATOS, V. C.; GONDIM, A. P. S. Automedicação na adolescência: um desafio para a educação em saúde. Ciência \& Saúde Coletiva, v. 16, n. 1, p.1651-1660, 2011.

SILVA, T. V.; LEDA, L. R. Intervenções educativas sobre parasitoses intestinais: aplicação de um jogo para alunos do Ensino Fundamental. Saúde \& Amb. Rev., Duque de Caxias, v. 7, n. 2, p. 2307, jul-dez., 2012.

SISTEMA NACIONAL DE INFORMAÇÕESSOBRE SANEAMENTO. Diagnóstico dos Serviços de Água e Esgotos - 2016. Brasília: SNSA/MCIDADES, 2018.

SOARES, T. M. et al. Fatores associados ao abandono escolar no ensino médio público de Minas Gerais. Educação e Pesquisa, São Paulo, v. 41, n. 3, p. 757-772, Sept. 2015. Acesso em 17 fev. 2021.

SOBRINHO, K. G. A. et al. Parasitas intestinais e o desempenho escolar de alunos de uma escola municipal em Teresina, Piauí. In: SILVA NETO, B. R. Prevenção e promoção de saúde 9. Ponta Grossa: Atena Editora, 2019.

VASCONCELOS, E. M. A priorização da família nas políticas de saúde. Saúde em debate, v. 23, n. 53, p. 6-19, 1999. 